\title{
Local hazard consultants in Switzerland - an innovative social learning element in a community of practice
}

\author{
Elisabeth Maidl *, Matthias Buchecker \\ Swiss Federal Institute for Forest, Snow and Landscape Research WSL, Zuercherstr. 111, 8903, Birmensdorf, Switzerland
}

\section{A R T I C L E I N F O}

\section{Keywords:}

Integrated risk management

Local hazard risk management

Community of practice

Social learning

Switzerland

Empirical risk research

\begin{abstract}
A B S T R A C T
Hazard risk managers in Switzerland face multiple challenges due to increasing damage potential resulting from climate change. This calls for a new integrative risk management paradigm that targets involvement of all relevant actors. An innovative program to strengthen knowledge was introduced in 2011 by the Federal Office for Environment and Nature (FOEN), in which locally anchored lay persons are trained as local natural hazard consultants (LNHC). The key objective of the program is to complement LNHCs' on-site experience with professional knowledge to support community crisis committees and tighten networks between actors. This study takes a social learning perspective in the context of this training program and interprets actors as a Community of Practice (CoP) in a social learning system. We evaluated the program with regard to its stated knowledge transfer goals and effects on the CoP. Applying a mixed-method study design, we conducted semi-structured interviews with cantonal training program coordinators $(n=12)$, followed by a quantitative survey of LNHC $(N=194)$. Results show an increased availability of knowledge, but the effects show better stability when participants are continuously involved in the CoP. We conclude that sustainable learning is enhanced by fostering the CoP and that risk awareness plays a crucial role in the implementation of the program.
\end{abstract}

\section{Introduction}

In the last decades, it has been increasingly recognized that disaster risk reduction with regard to natural hazards requires a paradigm change (Hyogo Framework for Action 2005-2015). Changing environmental conditions and the increase of values at risk exceed the capacity of traditional practices [1]. Applying this change in integrated hazard management not only implies acquiring new knowledge in hazard prevention, but also suggests a need for overcoming established routines and attitudes. As Aven and Renn [2] pointed out, the interplay between relevant actors needs to be the focus of risk management strategies to improve resilience. In other words, it requires a social learning process that allows for shared problem understanding and thus enables enhanced capacity to deal with the challenges of disaster risk reduction [3].

Swiss natural hazard management has shown such innovations, which represent seminal principles of integrated risk management in a new culture of risk. For instance, the National Platform for Natural Hazards PLANAT targets the paradigm change from traditional hazard control to a culture of risk and an integrated approach [4]. It has also been rather well adopted by cantonal agencies [5,6], but has not expanded into local risk prevention practice (Buchecker et al., 2016). Unlike centralistic states such as the Netherlands, local prevention practice cannot be defined and uniformly implemented by federal institutions. Requirements for sustainable management are well described, but there is little empirical evidence how to better enable adoption by local practitioners [7]. Therefore, it is crucial for future strategies in risk management to gain a better understanding of conditions that enhance acceptance of necessary innovations. Furthermore, the evaluation of flood events $[8,9]$, and especially the project "Optimization of warning and alerting OWARNA" [10], showed great potential to better mitigate the extent of damage caused by natural hazard, if locally available knowledge would be better available.

An alternative for federalist states would be to establish a Community of Practice within risk management institutions, by communicatively linking these institutions and thus enabling social learning. Integrated risk management embraces elements of social learning processes, as was investigated in other environmental fields, such as river revitalization $[11,12]$. Social learning has been confirmed to take place in local involvement processes $[13,14]$. As this form of social learning is

\footnotetext{
* Corresponding author.

E-mail address: elisabeth.maidl@wsl.ch (E. Maidl).
} 
not applicable in the context of risk prevention, we will emphasis knowledge exchange as a locus of social learning, which has not yet been empirically evaluated in this context.

In this study, we address this knowledge gap by investigating an educational intervention. The Federal Office for Environment and Nature in Switzerland (FOEN) launched a program for training locally anchored lay persons as actors in local hazard risk mitigation, who become known as Local Natural Hazard Consultants (LNHC). The implementation of this program is considered to be complementary to integrated risk management strategies and meant to create a dynamic link between national and local risk practices. In their function, though established in differently shaped processes, there are similarities with the volunteer civil protection organizations in Austria and Italy who also ensure a link between national and local risk prevention, and similarities to lay persons involvement in the UK in doing weather observations [15].

\section{Background and theory}

\subsection{Training of local natural hazard consultants: an educational invention}

An analysis conducted in Switzerland, on behalf of the Federal Office for Environment and Nature (FOEN), revealed that avoidable damages occur during natural hazard events due to a lack of locally available knowledge and insufficient interaction between experts and persons in charge in the authorities [10]. Therefore, the concept for a training program was developed to educate local inhabitants, who know their municipalities and their local area well. The vision was to complement their experience and knowledge about local conditions with basic expert knowledge on integrated risk management, which they would gain during the training (for learning objectives see Fig. 1). According to the original concept, they were not meant to be decision-makers, but rather provide information on local conditions and data, such as from the Common Information Platform for Natural Hazards GIN. As an element within the integrated risk management paradigm, they function as a link between the national strategy and the local sphere.

To achieve this goal, participants in this program receive training on natural hazard processes, meteorological conditions, prevention measures, administrational structure of risk management, and use of the GIN. Training lectures on these topics were developed at the federal level, and a coordinator in each canton was charged with organize the training the LNHC. Since participation in the program is voluntary, the FOEN has to gain acceptance and motivate coordinators to implement the concept. These coordinators also act as multipliers of the idea in their canton as they communicate with local municipalities and involve them in the program. As a first step, courses for coordinators were organized, and by June 2013, 11 cantons had taken part in the program. Out of these, eight cantons had already trained local consultants, and four additional cantons planned to do so.

A key goal of the LNHC program is to support the local crisis committees on site; before, during, and after an event, by providing locally available knowledge. According to the stated concept of the program, the consultants are to be integrated in the local, or regional, crisis committees who are charged with taking action in case of an event. The LNHCs' broader role is to foster the integrated risk management paradigm and trigger the change of routines down to the local level. Most of them are new participants in the practice of risk management, and receive training, in which not only knowledge on hazards is spread, but also on the way risk management is meant to function. A further key goal of the program is to strengthen and broaden networks in order to enhance information flow and exchange of experiences between regions. As the program runs in growing numbers of cantons and communities, new ties and exchange networks emerge, which contribute to a certain level of overall hazard preparedness in Switzerland. Acceptance of the program is achieved by practical demonstration and by using

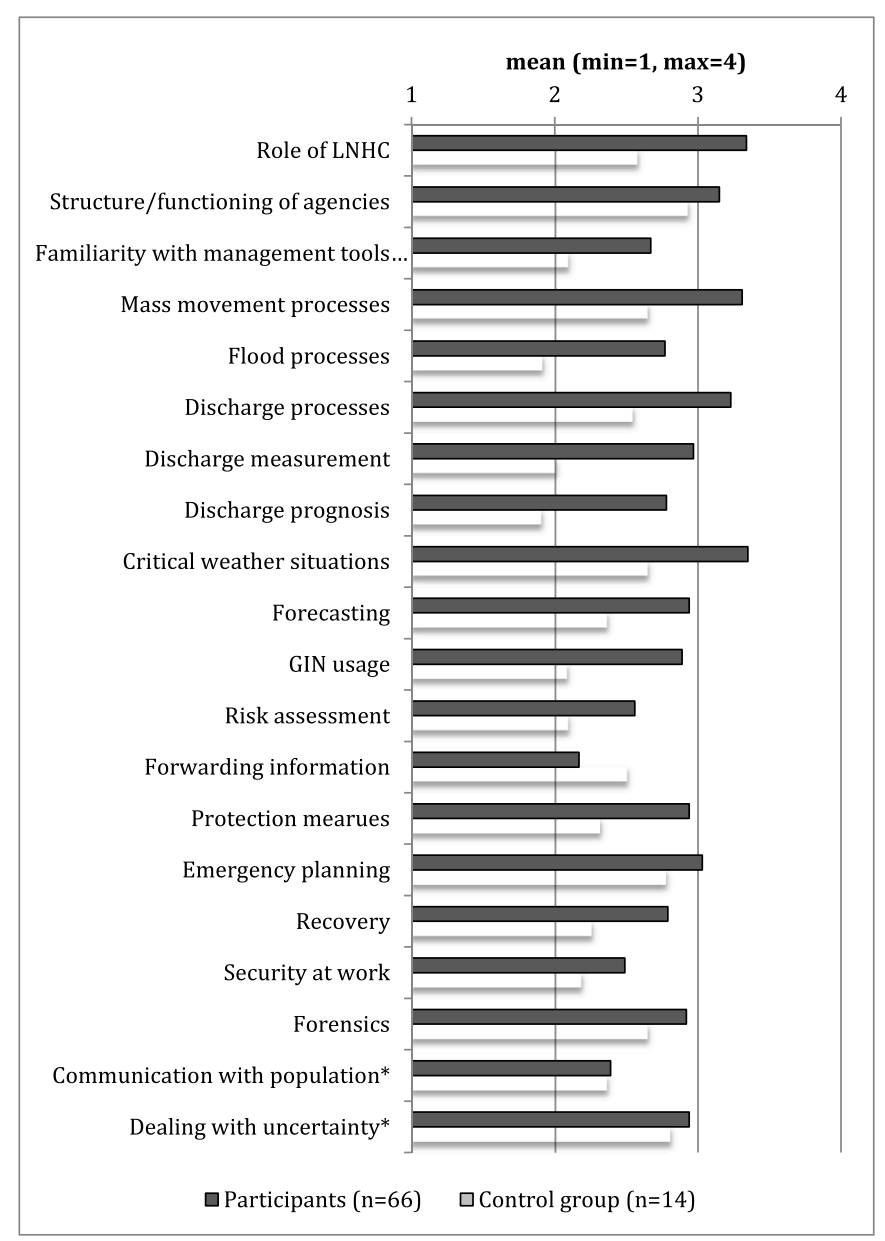

Fig. 1. Self-reported familiarity with training material or topics: mean values of participants and control-group, * These topics were not part of the content of training courses. We added these items to the questionnaire, because they were highlighted by coordinators as key challenges in risk management.

experiences from a pilot program in the canton of Berne in 2011 from which other cantons can benefit and draw conclusions.

The LNHC provide consultancy rather than make decisions so their training focuses on achieving and forwarding information, such as relevant data on weather events or warnings using GIN, which enables them to serve as a link between the operational and the expert level in risk management. As a newly trained participant in these procedures, their consultancy also brings new and integrated management ideas into these procedures to fill knowledge gaps. The federal situation analysis OWARNA revealed that the crisis committees were often overburdened in case of an event [10]. The LNHC are civilian and not members of the expert bodies, in which the professional firemen, civil protection officers and other local officers typically come together. The role of LNHC, according to the federal concept, is to assure that the available information is used, but the range of competences is extendible, depending on the specific cantonal design of the LNHC program. The role of LNHCs is meant to be supplementary to professional officers. The requirements for participation in the training program, as it was originally conceptualized by the FOEN, were that the applicant should have a good knowledge of the site, an affinity to natural hazards, and availability in case of an event. $\mathrm{LNCH}$ receive an allowance for their engagement, but are not employed by the municipality or the canton. Many of them are former professionals in the area of hazard protection, or are foresters or farmers who are familiar with the local topography and prior hazard events. In some cantons, the national concept has been adapted in a way that experts already employed in natural hazard management complete 
the training as continuing education. The ability of cantonal authorities to make adaptations according to specific conditions and preferences is foreseen in the national strategy. This is not only due to federalism and the associated need to gain acceptance for the program, but also to the heterogeneous conditions in the cantons. The concept is flexible so cantonal coordinators can create further goals and may adjust the original concept to fit local conditions and requirements.

The invention of LNHC is embedded in a social learning environment. It is an expression of a political culture in which flexibility and adaptability of the whole system, rather than the preservation of structures, is intended. The flexibility of the concept itself reflects the integrated management paradigm, which is about linking actors, knowledge, and procedures to make use of available resources over all stages of the risk management process; namely mitigation preparedness, response, and recovery. According to the official strategy in Switzerland, this implies enhancing all actors' contribution to protection against natural hazards; in particular those of individual property owners. All responsible actors need to be involved, which means not only to apply one type of measure but rather the full spectrum of possible measures, and training LNHC is one approach to achieving this. It is built upon the role of knowledge in risk management and therefore serves the purpose of providing and spreading comprehensive information about natural hazards risks.

The LNHC program is possibly an innovative example also for other countries. A literature review at the time the Swiss program was launched, did not reveal a comparable national programs and it is more common in other European countries to involve locals as volunteers after an event. Although, the benefits of strengthening local resilience by community-based, or bottom-up, strategies are highlighted in theory $[16,17]$, national strategies tend to lack foundation in local context [18]. Nevertheless, similar programs could be found. For instance, in Austria, and in the Italian Alto Adige region, there is a tradition of local voluntary fire brigades. The fire brigade volunteers today are also trained on risk assessment; even though the primary focus is on emergency management. LNHC, according to the original federal concept, however have not been involved in any form of local risk management before participation in the program. This is a key aspect, because the newly trained LNHC are meant to provide complementary support and relief to the existing committees. In the UK, there are so-called local flood hazard champions, who usually become active after an event. In some communities, members may choose to volunteer as « flood wardens » to help with the local Environment Agency. This program differs from the Swiss LNHC, because there is no consistent national concept as a base.

\subsection{Social learning in $\mathrm{CoP}$}

As a theoretical framework, we chose the theory of social learning. The LNHC program targets not only participants' individual learning progress, but is meant to improve networks, in which commonly shared tools are introduced, and elements of integrative risk management are anchored at all levels of risk management. Social learning prominently emerged with the work of [19]. Starting from a psychological perspective of learning as a cognitive process, he increasingly recognized the social context of learning, i.e. interactions, shared behaviours, and attitudes and developed a more social constructionist view (1986), in which participants of a learning process at the same time act as shapers of the learning context. In this process of change, they not only gain knowledge but also a mutual understanding of other interests, attitudes, and behaviours [20]. Learning is enhanced by communicative action when actors of different backgrounds work together. They align their problem perspectives and gain an understanding of interdisciplinary challenges, which is the case in integrated management [20,21].

In the field of integrated risk management research, social learning is so far a new concept. We therefore make use of insights derived from its application within sustainable resource management research [22-24]. We particularly make use of Reed et al.'s definition (2006), according to which social learning is "a change in understanding that goes beyond the individual to become situated within wider social units or communities of practice through social interactions between actors within social networks." This definition prominently emphasizes the element of "change". The subject of change occurs on three different levels, which are shown in Table 1:

The individual learning process in the LHNC project is a change of knowledge as an effect of course participation. We observed such changes in terms of attitudes, expectations, and beliefs on the micro level. On the meso-level, change occurs by interaction in networks, and has effects on the macro level of risk management institutions and paradigms.

We use the concept of a CoP $[25,26]$ to investigate, how individual and social learning are related among these levels. A CoP consists of members who do are not necessarily aware of each other, but contribute to the common goal of natural hazard management. They are part of a broader context, in which all the interactions and knowledge transfer is embedded [27]. explain that this context within the CoP of hazard risk management is strongly shaped by the common use of tools, and exchange of knowledge and attitudes. Therefore, we consider social learning as an adaptive development that serves the adaptability of the system itself. The ability to learn fosters flexibility and adaptability, which are both pre-conditions and outcomes of social learning, and therefore important for the institutionalization of integrative risk management. One of the key goals of integrative risk management is to keep risk management flexible and adaptive in a changing world, which is met by providing a learning environment [28].

[29] identified a problem in the application of the social learning theory: the concept is often confused with pre-conditions or methods, such as stakeholder involvement in decision-making [11,13,24,30] propose a broader understanding of social learning than mere cooperation. Knowledge transfer can, but does not necessarily, lead to sustainable behaviour change. We therefore consider Polanyi's [31] concept of "tacit knowledge", which Darby et al. (2006) regard, in their notion of knowledge rooted in experience, as more than knowledge about facts. The core advantage of this is to understand that behaviour change occurs as a result of changing action. In the LNHC program, tacit knowledge is adopted in new routines and common reflection, which provides space between individuals and local organizations [32] where these levels are linked. Social learning in this broader view makes interactive ways of learning more understandable [33,34]. In addition to the top-down knowledge transfer, the vertical, bottom-up transfer and collaborative learning come into play $[35,36]$. Learning among peers, such as by helping each other to find new solutions, accelerates and deepens progress more than if it is taught by an instructor [37].

Social learning systems consist of constitutive elements including boundary processes towards the outside, and shaping identities within the particular CoP [26]. With regard to the LNHC, external boundaries are topics other than natural hazard management (e.g. river restoration), organizational boundaries between departments and, on the individual level, identity. LNHC is not a profession or major task in the participants' agenda. Renn (2010) points out that risk-related knowledge is complex, uncertain, and ambiguous. By educating lay persons, this complexity is broken down to a simpler and everyday form in the local context. This has integrative potential on local actors and their

Table 1

Levels of change.

\begin{tabular}{ll}
\hline Level of change & Subject to change \\
\hline Individuals involved in the LNHC & Knowledge, attitudes, beliefs, expectations, \\
program & behaviour \\
Interaction between individuals & $\begin{array}{l}\text { Network structure, shared tools, exchange (of } \\
\text { in networks }\end{array}$ \\
knowledge gained at individual level) \\
management community & $\begin{array}{l}\text { Risk management institutions (implementation } \\
\text { of paradigm change by the LHNC program) }\end{array}$ \\
\hline
\end{tabular}


understanding of, and attitude towards, public risk management.

The integrated risk management idea is promoted by the federal office, but is implemented under the charge of individual cantonal officers, and takes place in concrete procedures on the local level in heterogeneous settings. The idea is passed in boundary processes from the federal level to the cantonal level, and from there to the local communities. We investigate what change is happening on the way, and in what form it reached practitioners at the local level. We assume that the original concept is shaped and adapted within the CoP.

By investigating knowledge transfer in the LNHC program, we further identify effects, challenges, and limitations. The program uses existing social capacities in local risk management and thereby provides insights into the implementation of new elements in a current set of routines. The implementation of the LNHCE program is the social learning process in the focus of our study. We conceptualize key elements of social learning in $\mathrm{CoP}$ as follows: knowledge as familiarity with course material, network effects as changing contact structures, role identity as the role understanding of LNHC in risk management, norms as attitudes towards risk management, and trust as trust in risk management. These are continuously reshaped during the implementation process.

\subsection{Aim of the study}

Although education and training are regarded as means of social capacity building for improved hazard preparedness [38], no scientific evaluation of such a training program for adults is available so far. Therefore, our study first provides empirical results on the potential effects of adult training in natural hazard management. In particular we focus on one major research question, which serves the broader goal to better understand social learning: What conditions enhance the implementation of an innovative intervention (LNHC) in Swiss hazard risk management? We distinguish two partial questions:

1) What individual learning results could be achieved (KT)?

2) What social learning effects are observable (CoP)?

The study evaluates the training program according to the goals as expressed in the original FOEN concept, and additionally according to a social learning perspective as elaborated in section 3 of this article. We focus on:

- Knowledge transfer: The evaluation of knowledge transfer includes not only the content of the learning material, but also the understanding of the role of LNHC and attitudes to risk management in the original FOEN concept. This broader concept of knowledge not only allows us to see the results of the learning process, but also to point out favourable or less favourable conditions.

- CoP and network structures: We investigate already existing and newly established personal networks of LNHC (duration, number and regularity of contacts with other actors) in the management of natural hazards. In this, we put a main focus on the exchange with other LNHC and involvement in crisis committees.

\section{Methods and study design}

Semi-structured expert interviews were conducted between January and March 2013 with 14 cantonal coordinators (in 12 of the 26 Swiss cantons) $)^{1}$ and two program leaders at FOEN, including cantons that were not willing to implement the program. The purpose of this

\footnotetext{
${ }^{1}$ In most cantons one person is responsible for the implementation of the program. In cantons with shared responsibility, both coordinators were interviewed. This was the case in Nidwalden/Obwalden (two half-cantons that implement the program together), and Solothurn.
}

qualitative study was to understand the conditions under which the program was accepted by the cantons, to evaluate knowledge transfer, and to serve as a basis for the design of an empirical questionnaire.

In a second step, the standardized survey for participants of the LNHC training program was conducted. During June and July 2013, a standardized survey of LNHC was conducted in five cantons where courses had already taken place. The questionnaire included items on the content of training courses, self assessment of competences with respect to the course content, and reported relevance of central tasks of an LNHC. Furthermore, questions were included to assess the respondents' degree of collaboration in the operational headquarters, attitudes toward risk management, expected effects of the introduction of NHC, means of dealing with insecurity, use of the information platform GIN, and assessment of the availability of risk management tools. Since we are interested in network effects in knowledge transfer, we also included items on respondents' contacts with other players in risk management, understanding of local management structures, and perceptions of major challenges in local risk management. The questionnaire concludes with socio-demographic items.

Sample:

Out of 194 nominated hazard consultants, 80 returned the questionnaire (41\%, see Table A1 and Table A2 for an overview). We also included persons in the sample who had already been recruited, but not yet trained $(n=9)$ as a control group. All of these new recruits were from the canton of Grisons, where the courses were in preparation at the time of the survey.

The canton of Berne had applied the concept in the original form as it was worked out by FOEN by training locally anchored lay persons as LNHC. Berne had the largest number of trained LHNC, but the other cantons were more sceptical about training lay persons as LNHC. Therefore, a majority of the LNHC $(n=49)$ had a professional background related to natural hazards and about the half of those $(n=24)$ were additionally engaged as a volunteer in hazard protection. The average time of professional experience was 22 years, with an average of 17 years of volunteering. Only $14 \%(n=10)$ of the sample were lay persons without any pre-educational background. Most participants (n $=32$ ) were present on $2-4$ course days. The differences in the number of training days are a result of different stages of program implementation as well as the conceptual design. Training for lay persons comprises more course days than training of experts (e.g. in Lucerne). The sociodemographic characteristics of the respondents are shown in Table 1.

\section{Results}

In this section, we present the results of the qualitative interviews with cantonal coordinators. Among the factors that influence whether the LNHC program was implemented in a particular canton, we found individual as well as structural conditions. The semi-standardized expert interviews with cantonal coordinators revealed, as a key result, that cantonal approaches to hazard risk management differ considerably. Cantonal risk management in the Swiss federalist context is autonomously organized by the cantons, which pays respect to the heterogeneous nature of risks, administrative structures, and human and financial resources. These context factors also frame the implementation and adaptation of the LNHC program. The decision whether it is implemented is further influenced by the coordinator's attitude towards the FOEN concept, their risk awareness, and special vulnerabilities in the cantons.

Furthermore, we found that many coordinators are part of a hazard management network in which they share ideas and experiences. However, not all are involved to the same degree. Networks are especially strong between neighbouring cantons, and cantons with the same language (French or German). Therefore, it is not surprising that the canton Ticino; the Italian speaking canton, follows its own approach towards hazard risk management. It is especially interesting that the canton Ticino already began to develop its own risk maps and to train 
hazard consultants 20 years ago. Similar training events had also been implemented in the canton of St. Gallen and Valais. The coordinators of these cantons took notice of the training program and the course material provided by the FOEN, but did not change existing structures.

\subsection{Enhancing factors for adoption of the LHC program}

As introduced in section 2.1, cantons decide over participation in the program, and its adaptation. From the beginning, the concept was designed to gain the cantons' acceptance and convince them to implement and adjust it. In the context of Swiss direct democracy, its implementation is anchored in a political culture that appreciates diversity of needs and interests. This demands flexibility and patience in implementing long-term programs. At the time the survey was conducted, the pilot phase of the program was finished, and the expectation was to have participation by $80 \%$ of the cantons (that is 20 of the 26 cantons) within 10 years. Although the term 'social learning' is not part of the program designers' explicit vocabulary, the concept fulfils several characteristics of social learning, such as identification with common goals, adoption of norms, and using common tools to bond and strengthening the networks.

The federal and cantonal executives named the following main reasons for a positive attitude and high acceptance of the LNHC program:

a) Personal network The pilot course was conducted in the canton of Berne, where close cooperation between program managers and federal agencies had already been established. The experience of this first example served as an orientation for decision makers in other cantons. Experiences, opinions, and positive and negative judgements were exchanged and discussed within formal and informal networks. Tight networks also have exclusive effects. Strong relations between neighbouring cantons go in line with weak crosslinking to other cantons.

b) Strong risk awareness In cantons in which the training program had already been conducted, executives typically showed high levels of risk awareness. In lack of such awareness, innovation in risk management is rather not seen as a priority task. Strengthening risk awareness and supporting potential multipliers in the cantonal departments can thus improve innovative capacity. Several interviewees pointed out that the dissemination of practical experiences with LNHC is an effective means to gain acceptance of the concept.

c) Obstacles to innovationIn some cantons, such as Wallis and St. Gallen, cantonal experts already function as local consultants. The LNHC program appeared less unfavourable for these cantons, in which the organisational structure of cantonal risk management comprised similar functions already. Although these interviewees expressed interest in integrating elements of the training material into their own training courses, their willingness to change existing institutions was rather low. A further influencing factor is that human and financial resources are not equally available in all cantons.

d) Topograph y and type of risks Willingness to invest in the training of LNHC tended to be higher in Alpine cantons. However, a high-risk situation does not necessarily result in high motivation for the program. As risk maps show, especially midland cantons are prone to hazards, but the occurrence of events is less frequent, and risk awareness is rather low. Furthermore, cantons that are less frequently affected by hazards also tend to rely on support from neighbouring cantons, where the personnel are more experienced.

\subsection{Results of the LNHC survey}

In this section, we present the results of our standardized survey of already trained LNHCs $(n=66)$, and a control group of recruited LNHC ( $n=14$ ). Inclusion of participants from the early stage of program implementation in the canton of Grisons allowed us to compare the trained LNHC, who had already been exposed to the lessons, with the group of recruited LNHC. The trained LNHC represent heterogeneous backgrounds, whereas the control group mainly consists of experts (foresters), since the canton of Grisons focused on foresters as LNHC candidates.

\subsubsection{Effects of educational program on knowledge transfer}

On average, the participants have become familiar with the topics discussed in the courses (Fig. 1) and show feelings of competence. The mean values are significantly lower for the control group than for the already trained participants. All participants, regardless of their professional background, reported a knowledge gain in all fields after the training. The transfer of knowledge significantly correlated with the number of visited course days $(\mathrm{r}=.488, \mathrm{p}<.001)$. The participants' heterogeneous background of skills and knowledge results in variation in competence patterns. Conducting explorative factor analysis, we identified three such patterns: (1) strength in management and communication, (2) data expertise, and (3) operational skills on site (see Appendix, Tab 1). Professionals are rather competent in working with data, while lay persons' skills provide a broader, but less deep, spectrum of competences, including social skills.

For all participants, primary areas of weakness appear to be in the fields of 'information flow', which is considered to be a key task of LNHC according to the original FOEN concept, and in 'communication with the population', which was however not part of the training courses. Furthermore, 'security at work' and 'risk assessment' are areas of unfamiliarity. Dealing with uncertainty (Fig. 2) was less an issue than we expected. Social skills and good integration in the Crisis Committee are advantageous in dealing with uncertainty.

\subsubsection{Feeling of competence and role understanding}

The target group for participation in the program were people who combined familiarity with local circumstances with an affinity to dealing with natural hazards. Considering the goals of the original FOEN concept, the role of LNHC is intermediary between agencies and practitioners in risk management, in particular between the local Crisis Committees and the cantonal agencies. Therefore, trained competences in dealing with data (e.g. the Geological Information Platform GIN) are important. Nevertheless, it is more crucial for the success of the program that LNHC become accepted and are acknowledged within the committees.

Fig. 3 shows which competences the respondents already had before course participation, which were achieved in training, and which they lack. Achieving expertise with GIN was a key result of the training. A majority of the LNHC in the sample (70\%) gained this competence during the training, whereas only $10 \%$ were familiar with GIN before course participation. The collection of meteorological data was a further competence that many $(40 \%)$ respondents achieved during the LNHC courses. The most widespread competences they already had before training, were weather observations and on site risk-assessment. A majority of the respondents (79\%) considered 'public awareness raising' (informing inhabitants) a major challenge, which is higher than the share of respondents, who consider 'availability of financial resources' (61\%) or 'availability of personnel resources' (44\%) challenging.

Fig. 3 shows the respondents' importance rating of particular competences, which reveals their understanding of the role of an LNHC. We identified three common patterns: outdoor risk assessment, communication, and dealing with data (typically experts). This confirms the patterns found in familiarity with training material (Appendix, Table A3, Table. A1), and shows again the value of heterogeneous backgrounds of LNHC to enrich available competences on site. The individual background, i.e. the competences the respondents already had before participation, influence the rating they gave to the key skills that an LNHC should have.

It was interesting to see that the comparison of LNHC with the 


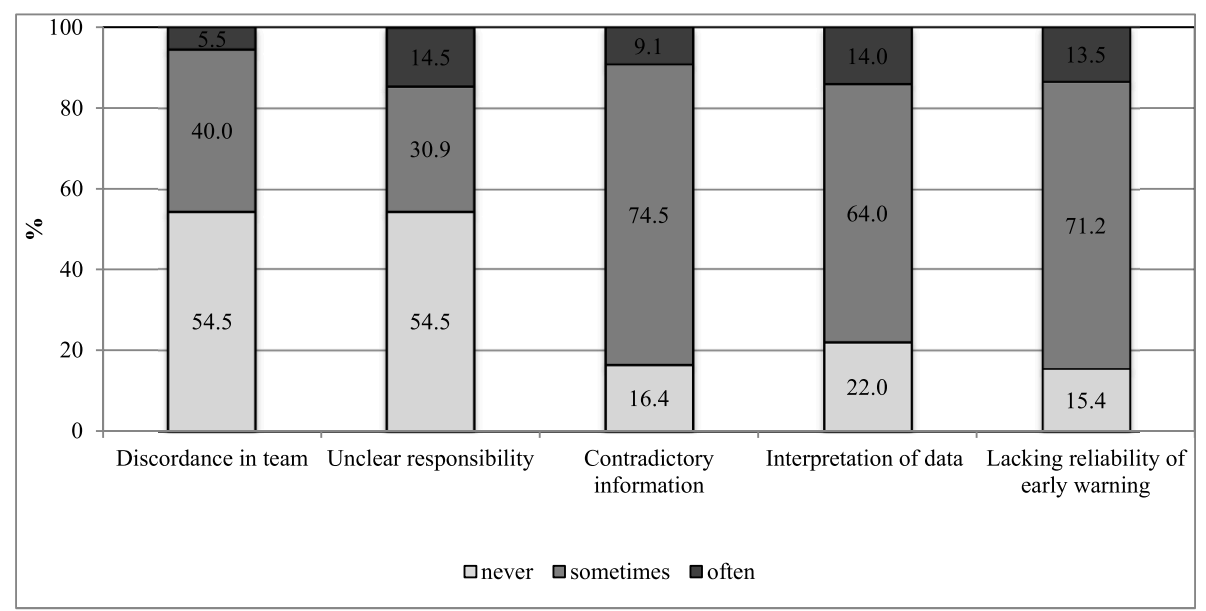

Fig. 2. Uncertainty (Basis:only participants, $n=66$ ).

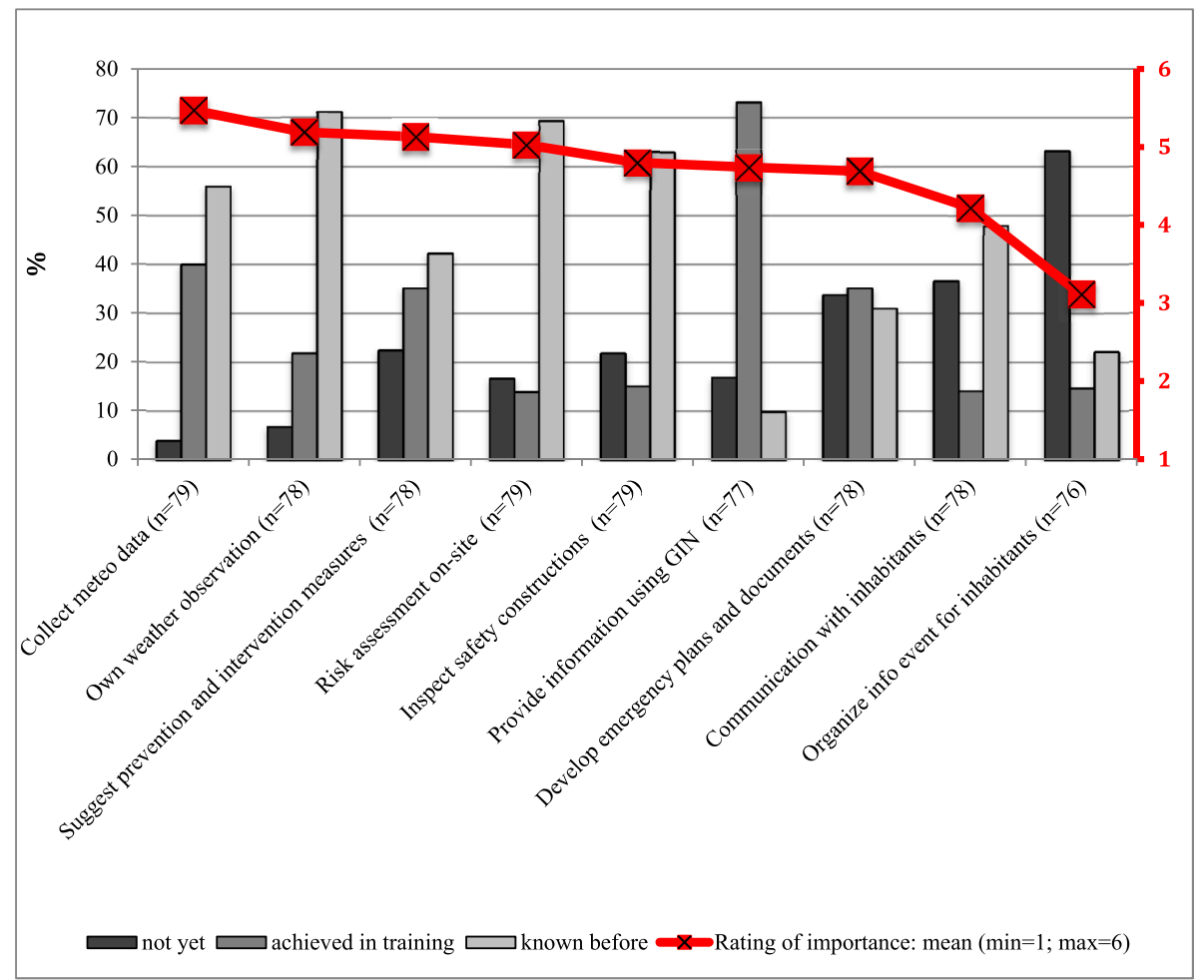

Fig. 3. Feeling of competence and role understanding of LNHC: comparison before and after course participation (right axis: relative frequency; left axis: rated importance of competences; basis: all respondents).

control group of experts (foresters in the canton of Grisons) revealed no significant differences. Furthermore, we found no significant differences between the cantons. The selection and adaptation of the FOEN's basic material was up to the cantonal coordinators, who did not have equal resources to implement this first round of the training program. In future, the content will be better adjusted to the specific training needs.

\subsubsection{Effects on expectations and motivation}

Participants share a positive attitude towards the LNHC program although a majority seem to have become more realistic during the course (Fig. 4). The comparison of attitude changes revealed that the integration of locally available knowledge and experience into professional risk management is a central expectation of the program. The control group already had a very positive view on local risk management and about the benefits of the program in particular. In contrast, newly integrated lay persons had relatively low expectations, which mirrors a rather weak self-confidence as newcomers in the community of risk managers. This is in line with the result that they feel less familiar with risk management procedures than professionals (see section 5.2.1). The involvement in crisis committees made them aware of difficulties, such as judging early warnings (see Fig. 2). Respondents reported several changes in their attitudes towards risk management (Fig. 5). Regarding the short duration of the program at the date of the survey, it is a surprisingly high level of self-reported change. Most participants agreed more strongly with integrated risk management statements than before but participants also developed a more critical view in some respects.

During on-going involvement, the new LNHCs' view converged with integrated risk management, which shows that they function as promoters of this new paradigm. One third of the respondents agreed more strongly with the statement that risk communication, or strengthening 


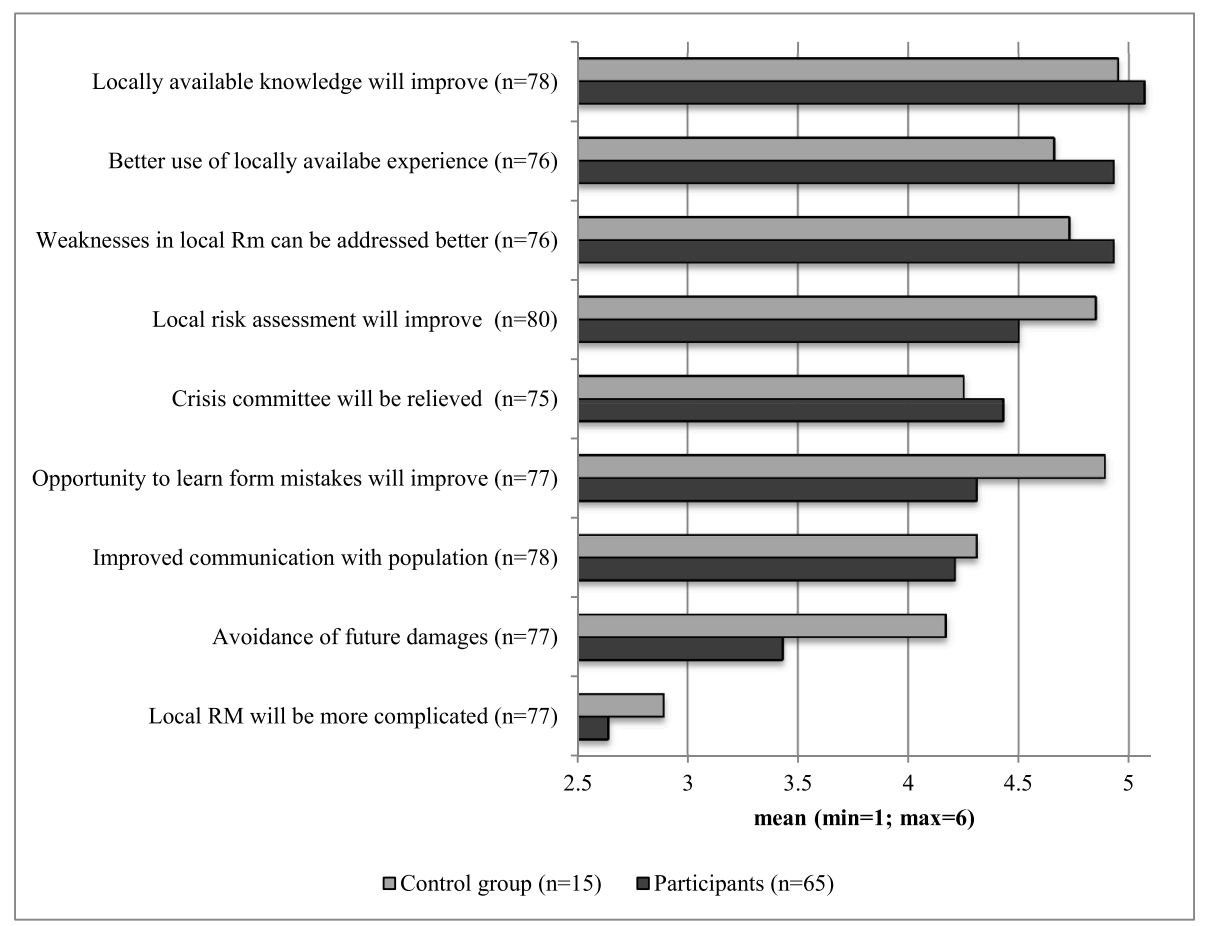

Fig. 4. Expected changes by the invention of LNHC (basis: all respondents). Note: Rm = Risk management.

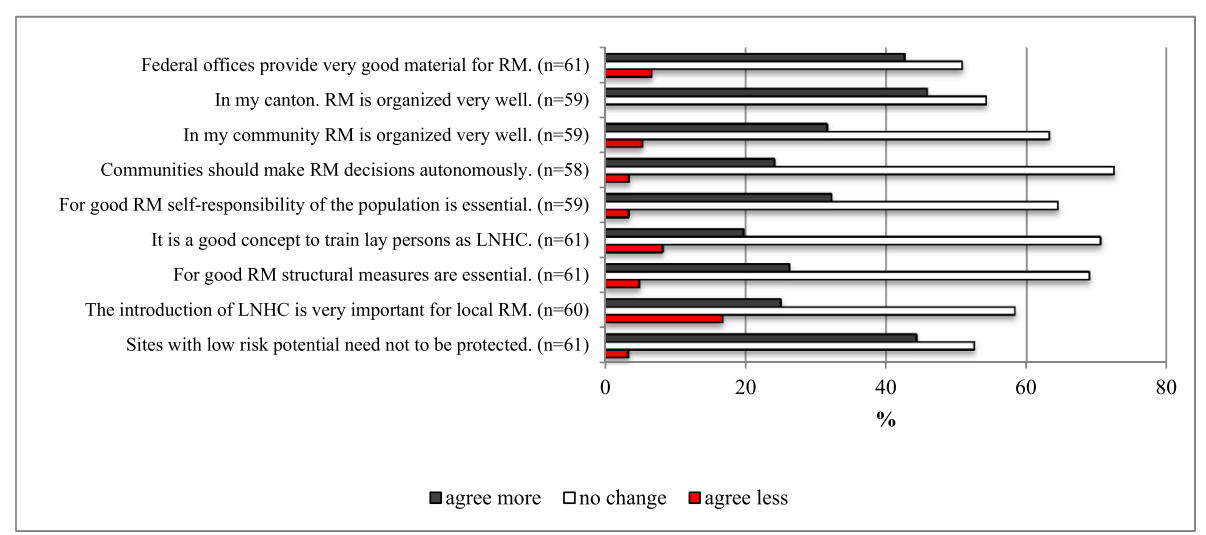

Fig. 5. Self-reported change in attitude towards hazard risk management (basis: LNHC participants).

self-responsibility, was essential for risk management. With respect to risk-based management (not protect low-risk sites), over $40 \%$ of the participants' agreement increased. However, more than a half of the LNHC report no attitude change in these respects. In the qualitative interviews, cantonal coordinators reported that course participants positively evaluated the quality of the training, the content, and the organization and communicated this evaluation to the organizers. It was beyond the scope of this study to cross-validate this evaluation.

\subsubsection{Availability and usage of common tools}

The awareness of availability of common tools in risk management determines the effectiveness of such tools.

In comparison to other risk management tools, such as hazard maps or emergency plans, early warning played only a minor role for the respondents. This finding is in line with the results of an internal survey ${ }^{2}$ of local municipalities in one the cantons that revealed that many tools were neither used nor known in many communities. Those respondents,

\footnotetext{
${ }^{2}$ Results of that survey were mentioned in one of the interviews.
}

who reported to have early warning available, assessed it as being very useful (Fig. 6). Among the common tools available for hazard risk management, the use of the Geological Information Network (GIN) was most prominent as a social learning element in risk management. Almost all of the respondents reported that the GIN was available to them. It is regarded as the most important instrument for LNHCs according to the FOEN concept. Only few of the respondents had worked with it before the training (Fig. 7), but after the training, most of them used it on a regular basis.

The respondents primarily used GIN when they recognized signs of a hazard event. In such cases, the majority of them check warnings, current measurement data, and prognoses. For the purpose of practice, the LNHC use data on prior events and simulations $(n=12)$. Interestingly, some respondents reported that they use GIN during an event. This reflects different interpretations of the role of an LNHC. Some cantonal coordinators emphasize the major task of an LNHC is to be outside, such as observing critical locations, rather than working from a desk. In contrast, others do not want them to be in the field, but rather to provide current meteorological data and survey warnings. Using GIN for analysis after an event is not very common. 


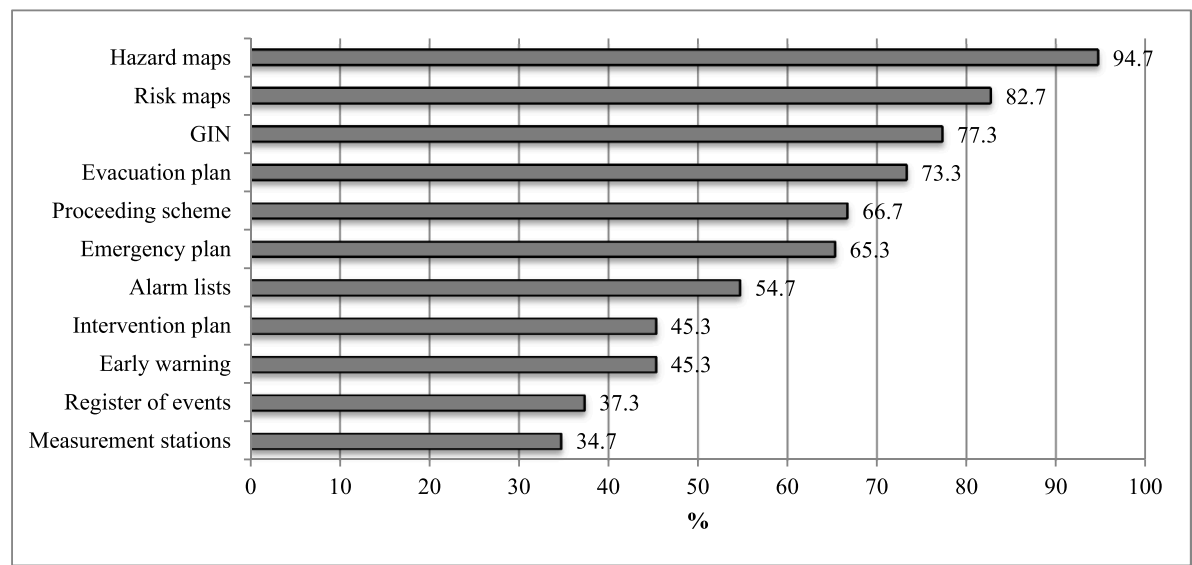

Fig. 6. Knowledge about risk management tools: availability in their community.

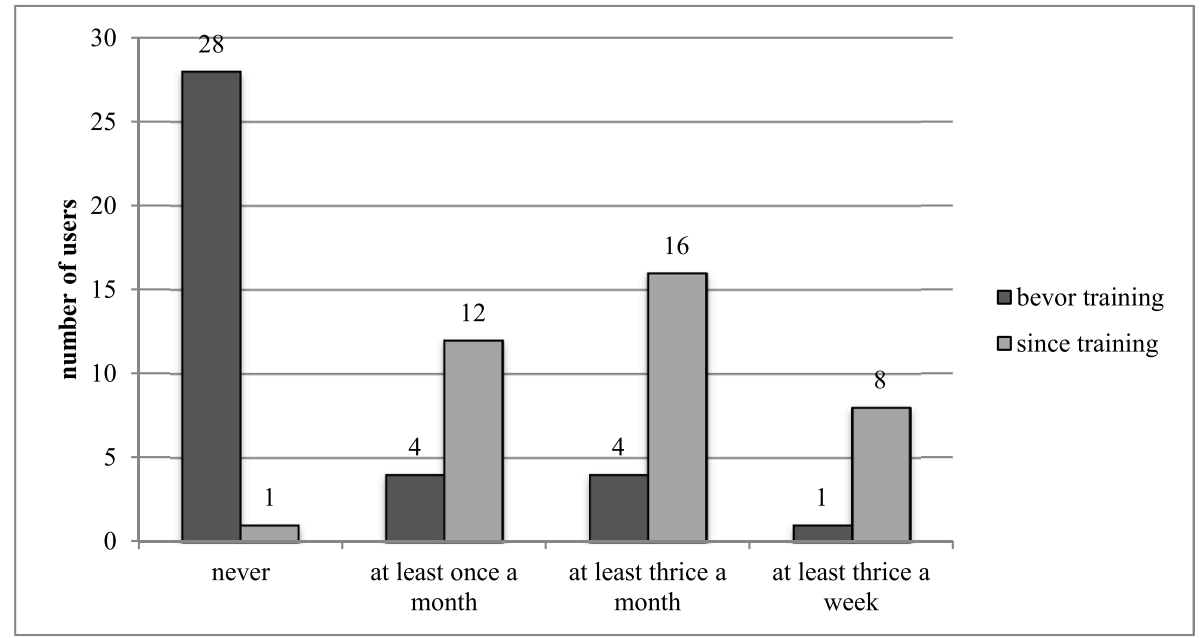

Fig. 7. Common Information Platform GIN usage: frequency before and after training.

\subsubsection{Development of personal networks}

Course participation enhanced the respondents' network structures. Results show that new contacts were more important to stabilize knowledge transfer and establishing LNHC as members of the CoP. Mostly, the participants made new contacts with peer LNHC, members of crisis committees, and civil protection personnel. The established

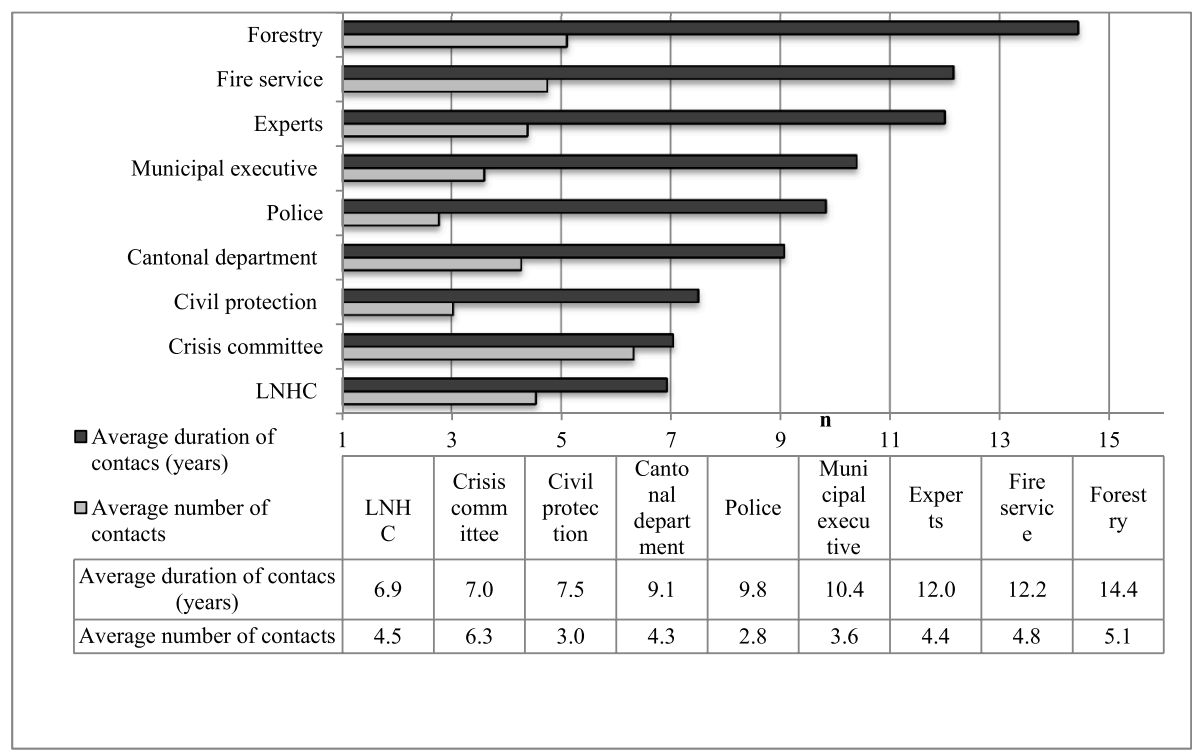

Fig. 8. Number and duration of contacts to other actors in hazard risk management. 
long-term contact structure mirrors that the participants are typically well integrated in their communities (Fig. 8). Most frequent contacts were to forestry, fire service, official experts on hazards and non-official experts on hazards, such as mountain guides. A majority of the LNHC reported no problems in combining their LNHC duty with other duties. Compared to lay persons, professional hazard consultants rather had difficulties to do so. Personal exchange among LNHC correlated positively with knowledge of the course content $(\mathrm{r}=.387, \mathrm{p}=.001)$, and was particularly high with increasing number of contacts $(\mathrm{r}=.437, \mathrm{p}<.001)$, and duration of contacts $(\mathrm{r}=.325, \mathrm{p}=.015)$.

There are also constraints to the development of contacts in some municipalities. Although $44 \%$ of the respondents reported to be strongly integrated within the Crisis Committee, a considerable proportion of $15 \%$ was not involved at all. The respondents were also asked to explain their personal experience regarding benefits and weaknesses in the development of contacts. They reported that: 1) The program focuses on the training and not on strengthening integration into Crisis Committees. Some committees were not aware of the existence of LNHC; 2) Community borders impede regional thinking: local actions are often limited to the own community and not cross-community; and 3) If members of the Crisis Committee lack trust in the LNHCs' competence, their opinion would not be taken seriously. Furthermore, responses revealed that adjusting one's own perspective according to other's experiences is a benefit of regional exchange meetings. A further benefit is the opportunity to seek contacts with inhabitants affected by hazards, and to take their experience into account for consultancy.

\section{Discussion}

The aim of this study was to better understand the role of knowledge transfer in social learning. We investigated social learning in the context of the LNHC (local natural hazard consultants) training program on three levels: (1) the individual learning process in terms of knowledge and competence gain, and changing attitudes, (2) changing network structures and effects on individual learning, and (3) the level of the hazard risk CoP.

(1) The individual learning makes more knowledge available at the local level (Fig. 1). We found increased familiarity with the topics of the courses, higher identification with the role of an LNHC, and changing attitudes towards integrated risk management (Fig. 5). According to the LNHCs' heterogeneous backgrounds, some topics were more easily absorbed than others, which results in patterns of competences: management and communication skills, data expertise, and operational skills on site. This illustrates ways in which LNHC contribute to the crisis committees. The more intensively the LNHC were involved in both, training and local hazard risk management, the more sustainable were the effects of the program. The longer the time since training had been accomplished, the more effects decreased. Survey respondents and coordinators expressed the view that further exchange meetings or education are necessary. Since learning on the individual level is basic for social learning, this contribution of the LNHC program to a social learning environment could be confirmed.

(2) Integration is a condition of social learning, since learning takes place and shapes the context in which it is embedded [29]. Furthermore, knowledge needs to be applied and the application leads it to become tacit knowledge, which is accompanied by attitude change [39]. From the social learning perspective, the role of GIN in the training program is of special interest. GIN brings users together to form networks in which they shape their attitudes, and also enhances identification with the role of an LNHC.

Involvement is related to the motivation to stay involved. As far as the knowledge gained in courses can be applied, the motivation is maintained, but the LNHC's motivation can be reduced if they don't gain experience in contributing to local crisis committees, and thereby stay in contact with other CoP members.

Networking among LNHC in the context of courses works well, but stabilizing contacts with other local crisis committees is more difficult, because these are not involved in courses. In some cantons, meetings of the crisis committee are only held in cases of emergency, so there is little opportunity to experience the role of being a member. Furthermore, some LNHC expressed that they did not feel accepted by the local crisis committees, which was often due to a lack of clarity about the role and competence of an LNHC. Individual motivation was also found to be an influencing factor on the level of cantonal coordinators. Especially, low awareness of risks resulted in reluctance to invest in innovation.

The process of recruitment of LNHC trainees in practice often reenforced existing networks by well-anchored locals. It has the potential to facilitate the discovery of latent public values and make them recognizable in risk management and encourages locals to develop a voice. We conclude that deliberative elements help to develop mutual understanding for other actors' perspectives to develop relational capacities [13,22].

As for individuals as subjects of learning, at the meso level, the cantonal structures developed new elements. The ideas and knowledge that formed the content of the courses undergo change in reference to cantonal circumstances. In the qualitative study, we found that the heterogeneous conditions of implementing the LNHC program in the Swiss cantons results in accordingly divergent means of implementation.

Learning at the level of networks is a central component that distinguishes individual from social learning. Learning is no longer only cognitive and intrapsychic, but the subject of learning is now also organizations and institutions. This effect is also demonstrable through the LNHC program. The organization of local natural hazard management has gained a new element with the LNHC, a new organizational form has emerged with the exchange meetings, and institutionally, integral risk management has become more widespread at the value level.

(3) Event analysis by the federal office had revealed lack of on-site knowledge (FOCP, 2007) as a weakness in risk management. Since the integrated management paradigm includes non-structural measures, such as education and better linking of actors, this question was answered by designing a program of knowledge transfer: the LNHC program. As [27] emphasize, motivation for change, collaborative action, and knowledge transfer is strong after an event. In their analysis of communication processes in risk-based planning at the community level, they also point out the role of research as a reflective element in the natural hazard management $\mathrm{CoP}$ in Switzerland. We propose that, apart from using the motivational effect hazard events, in order to overcome reluctance against innovation, it is promising to enhance participatory processes, bring new elements to existing networks, and foster experience exchange. On the macro level of CoP, the program had a social learning effects by strengthening a culture that is open for innovation and change.

The interview study showed that the pilot phase of the LNHC program succeeded in providing positive examples to encourage its implementation in other cantons. The main supporting factors for cantonal participation in the pilot phase of the LNHC program were (1) personal contact to program coordinators, 2) strong risk awareness, and 3) structural conditions of the cantonal hazard management. Strengthening the first two factors should contribute to innovative capacity. The LNHC program particularly strengthened the $\mathrm{CoP}$ as it made knowledge, tools, and contacts more convergent. In addition to formal structures, informal interactions need to be considered. Institutions shape behaviour by providing rules according to which individuals act and interact. At the same time the rules emerge from these interactions and are an expression of norms and values [40,41]. Therefore, any observable result of common action related to the LNHC program allows insights into related norms and values. As far as these are shared and reinforced in interactions, they represent a shared identity of the CoP members enhanced in cross-network building [42].

Our results indicate advantages and disadvantages of networks. Open networks are likely to foster flexibility and innovation. Closed networks, on the other hand, are likely to function as constraints. 
Coordinators, who were critical of the idea of training LNHC influenced the decisions in other cantons. This is expressed by the notion of "shadow spaces" [32]: there is a conservative effect in established network structures (see also [43]. Instead of enhancing a change in habits and structures, these mainly informal networks maintain continuity and stability, or technical lock-in [44]. Furthermore, we found that not all coordinators were in contact with others. Coordinators on the periphery of networks are more likely to drop-out and are less willing to implement the program.

Not all CoP dynamics are subject to strategic planning. Individual action is not primarily determined by rational choice, but also by psychological factors [45], administrative hierarchies [46], or individual goals [47]. This study shows that the permeable, multilevel structure of hazard management in Switzerland provides a ground for inventions and new ideas. Adaptability is an important element in risk management to deal with complexity and uncertainty (Renn 2010).

\subsection{Recommendations for future research}

We found evidence that knowledge transfer and network effects play an important role in social learning. New contacts could be established, but it was also found that the recruitment process of LNHC preserved existing network structures: cantons that closely interact with federal office moved closer to the center, and other cantons that are traditionally more distant move further to the periphery and continued to shape their cantonal risk management according to own regimes. However, the analysis of networks was restricted to LNHC participants and a broader network analysis would be necessary for the interpretation of network effects. Furthermore, an overview of characteristics and different types of cantonal, and/or regional regimes would provide a better understanding of conditions of social learning processes. Finally, long-term research and long-term studies would be required to thoroughly investigate social learning in this context.

\section{Limitations}

The results drawn from our study stem from an early phase of a program with a limited number of participants. Accordingly, the control group is small and biased, as it consists of the group of professional LNHC in the canton of Grisons. Although the results reveal observable effects of knowledge transfer within the frame of the LNHC invention on actors and networks involved in risk management, a deeper understanding of these effects and their conditions would require further research, especially long term studies with larger samples.

\section{Conclusion}

The LNHC training program intended to improve local risk management to better meet future challenges. The federal office FOEN developed a concept to overcome knowledge deficits in municipalities. We investigated this program using social learning theory in a community of hazard management practice. Social learning takes place in interactions and continuously establishes the characteristics of the CoP: in this case, the paradigm of integrated risk management. The program successfully transferred knowledge to the local scale, but there are also limitations to the concept. Innovations cannot be implanted, only embedded and are more likely to be adopted if there is awareness of risks and weaknesses in the current system. Therefore, it contributes to the improvement of the program to foster risk awareness. Furthermore, for the sake of sustainable change, the training needs to be continuous, or regular peer meetings need to be arranged. Otherwise the effects on knowledge transfer fade away quickly.

Continuity is also a contribution to keeping motivation high. For the program to be sustained and successful, not only the LNHC themselves need to be motivated, but also the other members of the crisis committees. The study showed that it can be frustrating to newly trained LNHC not to be involved on a regular basis, or not to have clear tasks. Maintaining motivation is related to expected changes and the belief that the individual's own work contributes to improvement. Therefore, appreciation and acceptance by members of established structures is important. Concretely, this means raising awareness of the benefits of the invention of LNHC in existing networks. We conclude that the perspective of social learning in a risk management community of practice provides insights into how to strengthen the implementation of innovations such as elements of integrated risk management. Especially networks, commonly shared tools, and horizontal and vertical knowledge transfer contribute to the CoP. Future research in the field should focus on long term effects and the sustainability of new elements in risk management, and effects on the local scale development, such as enabling paradigm change.

\section{Declaration of competing interest}

The authors declare that they have no known competing financial interests or personal relationships that could have appeared to influence the work reported in this paper.

\section{Appendix}

Table A1

Overview of the LNHC training program, interview study (January-March 2013) and the quantitative survey (June-September 2013)

\begin{tabular}{|c|c|c|c|c|c|c|}
\hline Canton & $\begin{array}{l}\text { Expert interview } \\
\text { conducted }\end{array}$ & $\begin{array}{l}\text { State of implementation of the } \\
\text { program } * *\end{array}$ & Number of LNHC* & $\begin{array}{l}\text { Background } \\
\text { LNHC }\end{array}$ & $\begin{array}{l}\text { Response } \\
\text { rate }\end{array}$ & Remark \\
\hline AG & 0 & 2 & 15 & Lay persons & 3 & \\
\hline AI/AR & 0 & 1 & $\mathrm{x}$ & & $\mathrm{x}$ & \\
\hline BE & 1 & 2 & $\begin{array}{l}99 \text { ( } 9 \text { of them } \\
\text { applicants) }\end{array}$ & Lay persons & 48 & Incl. Control group (5 out of 9 questionnaires) \\
\hline BS/BL & 0 & 0 & $\mathrm{x}$ & & $\mathrm{x}$ & \\
\hline FR & 1 & 2 & 14 & Experts & 3 & \\
\hline GE & 0 & 0 & 0 & & $\mathrm{x}$ & \\
\hline GL & 1 & 2 & 6 & Experts & 0 & \\
\hline GR & 1 & 1 & 0 (11 applicants) & & 9 & Control group \\
\hline JU & 1 & 1 & $\mathrm{x}$ & & $\mathrm{x}$ & \\
\hline LU & 1 & 2 & 5 & Experts & 4 & \\
\hline NE & 0 & 0 & 0 & & $\mathrm{x}$ & \\
\hline $\begin{array}{l}\text { NW/ } \\
\text { OW }\end{array}$ & 1 & 2 & 35 & Lay persons & $\mathrm{x}$ & Survey not conducted \\
\hline SG & 1 & 0 & $\mathrm{x}$ & & $\mathrm{x}$ & $\begin{array}{l}\text { Training program not implemented (individual } \\
\text { cantonal solution) }\end{array}$ \\
\hline
\end{tabular}


Table A1 (continued)

\begin{tabular}{|c|c|c|c|c|c|c|}
\hline Canton & $\begin{array}{l}\text { Expert interview } \\
\text { conducted }\end{array}$ & $\begin{array}{l}\text { State of implementation of the } \\
\text { program**}\end{array}$ & Number of LNHC* & $\begin{array}{l}\text { Background } \\
\text { LNHC }\end{array}$ & $\begin{array}{l}\text { Response } \\
\text { rate }\end{array}$ & Remark \\
\hline SH & 1 & 0 & 0 & & $\mathrm{x}$ & \\
\hline so & 1 & 0 & $\mathrm{x}$ & & $\mathrm{x}$ & \\
\hline SZ & 1 & 2 & 17 & Experts & 13 & \\
\hline TG & 0 & 2 & $\mathrm{x}$ & & $\mathrm{x}$ & \\
\hline TI & 1 & 1 & $\mathrm{x}$ & & $\mathrm{x}$ & \\
\hline UR & 0 & 2 & 3 & Experts & 0 & \\
\hline VD & 0 & 0 & $\mathrm{x}$ & & $\mathrm{x}$ & $\begin{array}{l}\text { Training program not implemented (individual } \\
\text { cantonal solution) }\end{array}$ \\
\hline VS & 0 & 0 & $\mathrm{x}$ & & $\mathrm{x}$ & \\
\hline Total & 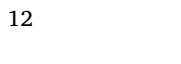 & $\begin{array}{l}\text { Implemented: } 9 \\
\text { Planned: } 3\end{array}$ & 194 & & 80 & \\
\hline
\end{tabular}

Table A2

Composition of the sample

\begin{tabular}{|c|c|c|c|}
\hline & Number of respondents & Average in years (mean value) & \\
\hline Age & 79 & 49 & - \\
\hline Sex & 80 & - & $94 \%$ male \\
\hline Professional background related to natural hazards (average: number of years) & 78 & 21 & $74 \%$ (yes) \\
\hline Volunteer background related to natural hazards (average: number of years) & 78 & 16 & $46 \%$ (yes) \\
\hline Lives in the region since & 79 & 36 & - \\
\hline Personal interest in natural hazards & 77 & - & $60 \%$ (yes) \\
\hline
\end{tabular}

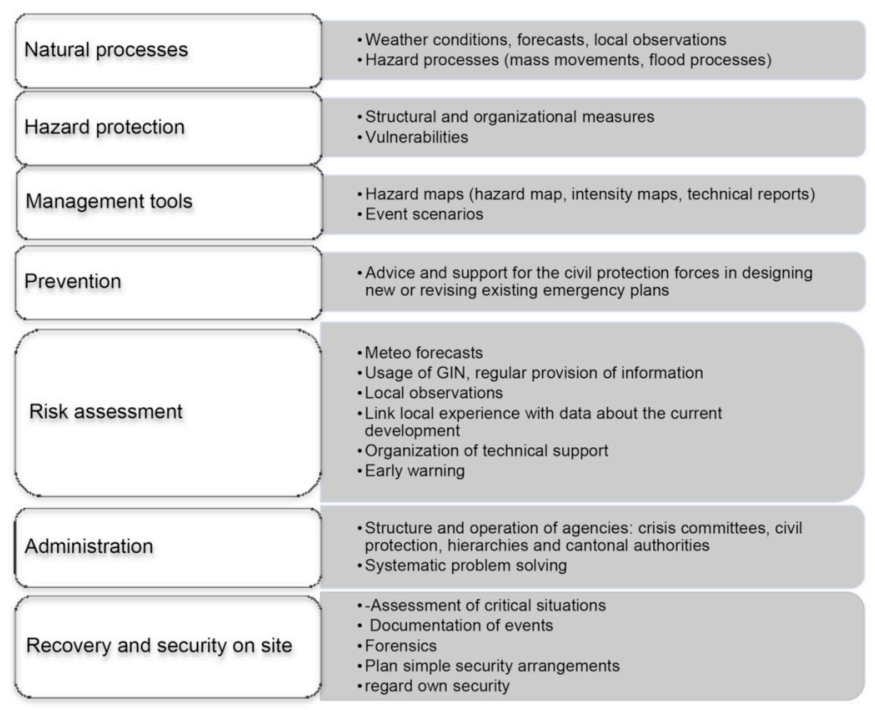

Fig. A1. Learning objectives: content of training material (according to the FOEN concept)

Table A3

Factor analysis: Familiarity with training material / self-reported competence

\begin{tabular}{lllll}
\hline & Data, measurement & Management/Communi-cation & Structural measures/Outdoor & Commu-nalities \\
\hline Familiarity with the role of LNHC & .465 & .076 & .309 \\
Familiarity with the functioning of Crisis Committees & .451 & .574 & .358 \\
Familiarity with weather processes & .546 & .465 & .315 & .506 \\
Familiarity with slide processes &. .001 & .219 & .535 & .505 \\
Familiarity with flood processes & .195 & .093 & .497 & .506 \\
Familiarity with runoff formation & .542 & -.200 & .182 & .140 \\
Familiarity with runoff measurement & .786 & -.155 & .614 & .458 \\
Familiarity with runoff prognosis & .742 & -.043 & .059 & .567 \\
Familiarity with protection measures & .229 & .063 & .341 & .639 \\
Familiarity basics of hazard risks & .317 & .066 & .057
\end{tabular}




\begin{tabular}{|c|c|c|c|c|}
\hline & Data, measurement & Management/Communi-cation & Structural measures/Outdoor & Commu-nalities \\
\hline Familiarity with GIN & .826 & -.017 & -.220 & .553 \\
\hline Familiarity with risk assessment & .205 & .398 & .459 & .758 \\
\hline Familiarity with evidence analysis on site & -.191 & -.176 & .792 & .434 \\
\hline Familiarity with knowledge transfer & -.058 & .744 & .155 & .658 \\
\hline Familiarity with communication with inhabitants & -.019 & .921 & -.194 & .686 \\
\hline Familiarity with security at work & -.214 & .536 & .530 & .713 \\
\hline Familiarity with recovery after an event & -.012 & .767 & .156 & .729 \\
\hline Familiarity with uncertainty & -.270 & .730 & .331 & .726 \\
\hline \multicolumn{5}{|l|}{$\begin{array}{l}\text { Extraction Method: Principal Component Analysis. } \\
\text { Rotation Method: Promax with Kaiser Normalization. }\end{array}$} \\
\hline
\end{tabular}

\section{References}

[1] L. Alfieri, L. Feyen, G. di Baldassare, Increasing flood risk under climate change: a pan-European assessment of the benefits of four adaptation strategies, Climatic Change 136 (2016) 507-521, https://doi.org/10.1007/s10584-016-1641-1.

[2] T. Aven, O. Renn. Risk management and governance: Concepts, guidelines and applications, Springer, 2010.

[3] E. Maidl, D. Bresch N., M. Buchecker, Social integration matters: factors influencing natural hazard risk preparedness-a survey of Swiss households, Nat. Hazards 105 (2020) 1861-1890, https://doi.org/10.1007/s11069-020-04381-2.

[4] PLANAT Plattform Naturgefahren Schweiz, Strategie Naturgefahren Schweiz, 2005. Available at: http://www.planat.ch/fileadmin/PLANAT/planat_pdf/alle_20 12/2001-2005/Ammann_Schneider_2004_-_Strategie_Naturgefahren_Schweiz.pdf. March 2016.

[5] J.T. Hess. Schutzziele im Umgang mit Naturrisiken in der Schweiz, vdf Hoschulverlag AG, Zürich, 2011.

[6] J. Hess, S. Lagger, R. Manser, H.P. Willi. Umgang mit Naturgefahren in der Schweiz. Bericht des Bundesrats in Erfüllung des Postulats 12.4271 Darbellay vom 14.12.2012, Federal Office for the Environment FOEN, Bern, 2012.

[7] P. Aldunce, R. Beilin, M. Howden, J. Handmer, Resilience for disaster risk management in a changing climate: practitioners' frames and practices, Global Environ. Change (2015) 1-11.

[8] G.R. Bezzola, C. Hegg (Eds.), Ereignisanalyse Hochwasser 2005, Teil2 - Analyse von Prozes-sen, Massnahmen und Gefahrengrundlagen. Bundesamt für Umwelt BAFU, Eidg, Forschungsanst. WSL. Umwelt-Wissen Nr, 2008, 0825. 429 S.

[9] G.R. Bezzola, W. Ruf (Eds.), Ereignisanalyse Hochwasser August 2007. Analyse der Meteo- und Abflussvorhersagen; vertiefte Analyse der Hochwasserregulierung der Jurarandgewässer. Umwelt- Wissen Nr. 0927, Bundesamt für Umwelt, Bern, 2009, 209 S.

[10] M. Brossi, F. Stoffel. Optimierung von Warnung und Alarmierung Schlussbericht in Erfüllung des VBS-Auftrages vom 1. November 2005, The Federal Department of Defence, Civil Protection and Sport DDPS, Bern, 2007.

[11] E. Mostert, C. Pahl-Wostl, Y. Rees, B. Searle, D. Tàbara, J. Tippett, Social learning in European river-basin management: barriers and fostering mechanisms from 10 river basins, Ecol. Soc. 12 (2007) 19. Available at: http://www.ecologyandsociety. org/vol12/iss1/art19/. March 2016.

[12] S. Menzel, M. Buchecker, Does Participatory Planning Foster the Transformation Toward More Adaptive Social-Ecological Systems? Ecol. Soc. 18 (2013).

[13] C. Pahl-Wostl, Transition towards adaptive management of water facing climate and global change, Water Resour. Manag. 21 (2007) 49-62.

[14] M. Buchecker, M. Fankhauser, R. Gaus, Finding shared solutions in landscape or natural resource management through social learning: A quasi-experimental evaluation in an Alpine region, Landsc. Ecol. (2021), https://doi.org/10.1007/ s10980-021-01274-y.

[15] T. Krennert, G. Pistotnik, R. Kaltenberger, C. Csekits, Crowdsourcing of weather observations at national meteorological and hydrological services in Europe, Adv. Sci. Res. 15 (2018) 71-76, https://doi.org/10.5194/asr-15-71-2018, 2018.

[16] International Strategy for Disaster Reduction ISDR, Living with RiskA Global Review of Disaster Reduction Initiatives. A Global Review of Disaster Reduction Initiatives, 2014. https://www.unisdr.org/files/657_lwr1.pdf.

[17] D. Butler, Sweetapple Ward, M. Astaraie-Imani, K. Diao, R. Farmani, G. Fu, Reliable, resilient and sustainable water management: the Safe \& SuRe approach, Global Challenges 1 (1) (2016), https://doi.org/10.1002/gch2.1010.

[18] B.L. Preston, R.M. Westaway, E. Yuen, Climate adaptation planning inpractice: an evaluation of adaptation plans from three developed nations, Mitig. Adapt. Strategies Glob. Change 16 (4) (2011) 407-438.

[19] A. Bandura, Social Learning Theory, Prentice-Hall, Englewood Cliffs, New Jersey, USA, 1977.

[20] M. Muro, P. Jeffrey, A critical review of the theory and application of social learning in participatory natural resource management processes, J. Environ. Plann. Manag. 51 (2008) 325-344.

[21] J. de Vente, M. Reed, L.C. Stringer, S. Valente, J Newig, Ecol. Soc. 21 (2016), https://doi.org/10.5751/ES-08053-210224.

[22] N.G. Röling, M.A.E. Wagemakers, Facilitating Sustainable Agriculture: Participatory Learning and Adaptive Management in Times of Environmental Uncertainty, Cambridge University Press, Cambridge, UK and New York, New York, USA, 1998.
[23] T. Jackson, Motivating Sustainable Consumption. A Review of Evidence on Consumer Behaviour and Behavioural Change, 2004. A report to the sustainable development research network [online]. Available from: www.sd-research.org. uk/researchreviews/documents/MotivatingSCfinal.pdf.

[24] C. Pahl-Wostl, The importance of social learning in restoring the multifunctionality of rivers and floodplains, Ecol. Soc. 11 (2006). Available at: http://www. ecologyandsociety.org/vol11/iss1/art10/. March 2016.

[25] J. Lave, E. Wenger, Situated Learning: Legitimate Peripheral Participation, Cambridge University Press, Cambridge, UK, 1991.

[26] E. Wenger, Communities of Practice and Social Learning Systems, vol. 7, Organization, 2000.

[27] N. Bischof, M. Eppler, H. Kienholz, Akteurskonstellation und Wissenskommunikation im Naturgefahrenmanagement der Schweiz, Schweiz. Z. Forstwes. 163 (12) (2012) 262-270.

[28] I. Fazey, J.A. Fazey, J. Fischer, K. Sherren, J. Warren, R. Noss, S. Dovers, Adaptive capacity and learning to learn as leverage for social-ecological resilience, Front. Ecol. Environ. 5 (2007) 375-380.

[29] M.S. Reed, G. Evely, I. Cundill, J. Fazey, A. Glass, J. Laing, B. Newig, C. Parrish, C. Prell, Raymond, L.C. Stringer, What is social learning? Ecol. Soc. 15 (2010). Available at: http://www.ecologyandsociety.org/vol15/iss4/resp1/. March 2016.

[30] P. Steyaert, G. Ollivier, The European water framework directive: how ecological assumptions frame technical and social change, Ecol. Soc. 12 (2007) 25. Available at: http://www.ecologyandsociety.org/vol12/iss1/art25/.

[31] M. Polanyi. Knowing and Being, Chicago University Press, 1969.

[32] M. Pelling, C. High, J. Dearing, J. Smith, Shadow spaces for social learning: a relational understanding of adaptive capacity to climate change within organisations, Environ. Plann. 40 (2008) 867-884.

[33] G. Bateson, Steps to an Ecology of the Mind, 1972, University of Chicago Press, Chicago, IL), 2000.

[34] R.L. Ison, C. High, C. Blackmore, M. Cerf, Theoretical frameworks for learningbased approaches to change in industrialised-country agricultures, in: M. Cerf, D. Gibbon (Eds.), Cow Learning for Change in Agriculture: Case Studies from Industrialised Countries, INRA, Paris, 2000, pp. 31-54.

[35] G. Elwyn, T. Greenhalgh, F. Macfarlane, Groups: A Guide to Small Group Work in Healthcare Management, Education and Research, Radcliffe Medical Press, Abingdon, Oxon), 2001.

[36] B. Wisner, P. Blaikie, T. Cannon, I. Davis, At Risk: Natural Hazards, People's Vulnerability and Disasters, Routledge, London, 2004.

[37] J. Surowiecki, The Wisdom of Crowds: Why the Many Are Smarter than the Few and How Collective Wisdom Shapes Business, Economies, Societies and Nations, Doubleday, London), 2004.

[38] C. Kuhlicke, A. Steinführer, C. Begg, C. Bianchizza, M. Brundl, M. Buchecker, B. De Marchi, M.D. Tarditti, C. Hoppner, B. Komac, L. Lemkow, J. Luther, S. McCarthy, L. Pellizzoni, O. Renn, A. Scolobig, M. Supramaniam, S. Tapsell, G. Wachinger, G. Walker, R. Whittle, M. Zorn, H. Faulkner, Perspectives on social capacity building for natural hazards: outlining an emerging field of research and practice in Europe, Environ. Sci. Pol. 14 (2011) 804-814, https://doi.org/10.1016/j. envsci.2011.05.001.

[39] S. Darby, Social learning and public policy: Lessons from an energy-conscious village, Energy Pol. 35 (2006) 2929-2940, https://doi.org/10.1016/j. enpol.2005.04.013.

[40] D.C. North, Institutions, Institutional Change and Economic Performance, Cambridge University Press, Cambridge), 1990.

[41] E. Durkheim, Rules of Sociological Method, Free Press, 1982, 1895.

[42] C. High, M. Pelling, G. Nemes, Understanding Informal Institutions: Networks and Communities in Rural Development, Invited Paper for Transition in Institute of Economics, Hungarian Academy of Sciences, 2005 (Budapest.Agriculture Conference).

[43] R.E. Kasperson, O. Renn, P. Slovic, H.S. Brown, J. Emel, R. Goble, J.X. Kasperson, S. Ratick, The social amplification of risk :a conceptual framework, Risk Anal. 8 (1988) 177-187.

[44] S. van Herk, J. Rijke, C. Zeverbergen, R. Ashley, B. Besseling, Adaptive comanagement and network learning in the Room for the River programme, J. Environ. Plann. Manag. 58 (2014) 1-22, https://doi.org/10.1080/ 09640568.2013.873364. 
[45] T. Grothmann, A. Patt, Adaptive capacity and human cognition: the process of individual adaptation to climate change, Global Environ. Change 15 (3) (2005) 199-213.
[46] J.G. Iwanciw, Promoting Social Adaptation to Climate Change and Variability through Knowledge, Experiential and Co-learning Networks in Bolivia, 2004. http: //www.lapz.nur.edu/resilienciaComunidAd (La Paz).

[47] P. Williams, The competent boundary spanner, Publ. Adm. 80 (2002) 103-124. 